\title{
Conversion rate and risk factors of conversion to open in laparoscopic appendicectomy
}

\author{
Nelson Rao Pushpanathan ${ }^{1,2, *}$, Mohd Nizam Md Hashim ${ }^{1,2, \star}$, Zalina Zahari ${ }^{3}$, Syed Hassan Syed Abd. Aziz ${ }^{1,2}$, \\ Wan Zainira Wan Zain ${ }^{1,2}$, Rosnelifaizur Ramely ${ }^{1,2}$, Michael Pak-Kai Wong, ${ }^{1,2}$, Ikhwan Sani Mohamad ${ }^{1,2}$, \\ Wan Mokhzani Wan Mokhter ${ }^{1,2}$, Maya Mazuwin Yahya ${ }^{1,2}$, Siti Rahmah Hashim Isa Merican ${ }^{1,2}$, \\ Zaidi Zakaria ${ }^{1,2}$, Andee Dzulkarnaen Zakaria ${ }^{1,2}$ \\ ${ }^{1}$ Department of Surgery, School of Medical Sciences, Universiti Sains Malaysia, Kubang Kerian, Kelantan; ${ }^{2}$ Department of Surgery, Hospital \\ Universiti Sains Malaysia, Kubang Kerian, Kelantan; ${ }^{3}$ Faculty of Pharmacy, Universiti Sultan Zainal Abidin, Besut Campus, Besut, Terengganu, \\ Malaysia
}

Purpose: Laparoscopic appendicectomy (LA) has several advantages over conventional open appendicectomy (OA). However, about $5 \%$ to $10 \%$ of LA patients still need to be converted to open surgery. Identifying risk factors that contribute to conversion to OA allows for early identification of patients who may benefit from primary OA. This study aimed to determine the conversion rate of LA to OA and to identify its associated risk factors among patients with acute or perforated appendicitis.

Methods: A retrospective review of medical records was performed among patients with acute or perforated appendicitis who underwent LA between December 2015 and January 2017. With the use of multivariable logistic regression analyses, the predictors of conversion from laparoscopic to OA were investigated.

Results: Out of 120 patients, 33 cases were converted to OA which gives a conversion rate of $27.5 \%$. Among 33 patients who were converted to OA, 27 patients $(81.8 \%)$ had perforated appendix, while in the LA group, perforated appendix cases consisted of $34.5 \%(\mathrm{P}<0.001)$. Histopathology of the appendix was the predictor of conversion from LA to OA (adjusted odds ratio, 8.82; 95\% confidence interval, 3.13-24.91; $\mathrm{P}<0.001)$.

Conclusion: The result from our study shows that the overall conversion rate for the study period was high. Patients with perforated appendicitis had a higher risk of conversion to OA. Therefore, preoperative diagnosis of perforated appendicitis may be paramount in predicting conversion to OA.

\section{Keywords: Conversion to open; Laparoscopic appendicectomy; Open appendicectomy}

Received: May 26, 2020 • Revised: Oct 19, 2020 • Accepted: May 14, 2021 Correspondence to: Mohd Nizam Md Hashim, M.Med (Surgery)

Department of Surgery, School of Medical Sciences, Universiti Sains Malaysia, 16150 Kubang Kerian, Kelantan, Malaysia

Tel: +60-9-7676777, Fax: +60-9-7653370

E-mail:drnizamkk@usm.my

ORCID: https://orcid.org/0000-0002-4066-6558

Co-Correspondence to: Zalina Zahari, Ph.D.

Faculty of Pharmacy, Universiti Sultan Zainal Abidin, Besut Campus, 22200

Besut, Terengganu, Malaysia

Tel: +60-9-6993187, Fax: +60-9-6993004

E-mail: zalinazahari@unisza.edu.my

ORCID: https://orcid.org/0000-0003-1459-8958

*Nelson Rao Pushpanathan and Mohd Nizam Md Hashim contributed equally to this study as co-first authors.

(C) 2022 The Korean Society of Coloproctology

This is an open-access article distributed under the terms of the Creative Commons Attribution NonCommercial License (https://creativecommons.org/licenses/by-nc/4.0) which permits unrestricted noncommercial use, distribution, and reproduction in any medium, provided the original work is properly cited.

\section{INTRODUCTION}

Appendicitis is the inflammation of the appendix and one of the most common conditions that require surgery. Worldwide the estimated lifetime risk of having appendicitis is 7\% to $8 \%$. Introduced by Semm [1] in 1983, laparoscopic appendicectomy (LA) has widely been accepted over the last few years as a standard approach to acute appendicitis. LA accounts for almost $75 \%$ of all appendicectomies in the United States [2]. The advantages of laparoscopic procedures have been frequently described with many factors such as better cosmetic outcome, lower wound infection rate, reduced postoperative pain, faster recovery time, and shorter stay in hospitals. The disadvantages are increased operative time, increased medical costs, and complication rate.

About $5 \%$ to $10 \%$ of LA patients still undergo a conversion to open surgery for multiple reasons [3-7]. Conversion from LA to 
an open appendicectomy (OA) can occur if intraoperative complications arise during LA or if the severity of the disease hinders a safe laparoscopy $[3,4,8,9]$. Multiple patient and disease factors such as male sex, age of $>65$ years old, complicated appendicitis (purulent with free pus, perforated, and abscess formation) or noncomplicated appendicitis, adhesions, technical difficulty, and duration of symptoms prior to presentation have all been identified as risk factors in conversion to open surgery $[5,6,10,11]$.

Conversion from LA to OA not only removes all the beneficial attributes of laparoscopic approach as highlighted, but it also increases cost and operating time [12]. This reason makes it beneficial to identify the related factors for conversion to open surgery so that the ideal approach can be planned for the high risk for the conversion group of patients. Hence, this study is aimed to determine the conversion rate of LA to OA and to identify its associated risk factors among patients with acute or perforated appendicitis.

\section{METHODS}

\section{Ethical approval}

An ethical clearance was obtained from the Human Research Ethics Committee of Universiti Sains Malaysia in Kelantan, Malaysia (No. USM/JEPeM/18040206). Informed consent has been waived by the Ethics Committee.

\section{Study design and setting}

This is a retrospective review of patients with acute or perforated appendicitis who were referred/treated or diagnosed and underwent LA at Hospital Universiti Sains Malaysia (HUSM) in Kubang Kerian, Kelantan, Malaysia from December 2015 until January 2017. HUSM is an academic, tertiary care center, and one of the largest hospitals in Kelantan.

\section{Participants}

Between December 2015 and January 2017, 120 patients with acute or perforated appendicitis who underwent LA met the inclusion and exclusion criteria. The inclusion criteria for this study were the age of 12 years old and above as the patients below 12 years old were managed by the pediatric surgery team, hence, excluded in our study, clinical diagnosis on presentation of either acute or perforated appendicitis, and patients who underwent LA during the study period. The exclusion criteria were any patients who had other acute abdomen diagnosis such as perforated viscus, ectopic pregnancy, pelvic inflammatory disease, cases with suspected malignancy, patients with palpable appendicular mass, and those with incomplete data or missing data or duplicated entries and loss to follow up.

The diagnosis of appendicitis was based on the presence of positive history and suggestive clinical examination findings; characteristic migratory abdominal pain, anorexia, nausea, fever, rebound tenderness, and leukocytosis. A combination of each of the signs and symptoms increases the probability of the diagnosis of appendicitis.

\section{Surgical procedure}

OA was performed through a Lanz incision and laparoscopic approach performed through $10-\mathrm{mm}$ infraumbilical camera port placement with 2 working ports of $5 \mathrm{~mm}$ at the left iliac fossa and suprapubic area using the Karl Storz Imagel S Laparoscopic System (Tuttlingen, Germany).

\section{Sample size estimation}

The sample size was calculated using 2 means and 2 proportions formula for both continuous and categorical variables, respectively to obtain the appropriate sample size for the factors associated with conversion from LA to OA. The calculation was done using the PS (Power and Sample Size Calculations, ver. 3.0.12). The final targeted sample size was determined by considering $20 \%$ drop-out rate. The estimated sample size for this study was 120 samples.

\section{Data collection}

This study involved secondary data collection. A retrospective medical record review of all patients with acute or perforated appendicitis who were referred/treated or diagnosed and underwent LA at HUSM over a 14-month period (December 2015 to January 2017) was performed. Patients' medical records were reviewed in detail to obtain patient demographics and clinical characteristics. All information needed is recorded in the data collection form to reduce bias. Variables that were required for the study were age, sex, ethnicity, histopathology of the appendix, temperature on presentation, duration of symptoms on presentation, and total white blood cell.

\section{Statistical analysis}

Demographics and clinical data were reported as frequencies or proportions for categorical data, means \pm standard deviations or medians (interquartile ranges) for continuous variables, as appropriate. Differences in patient demographics and clinical characteristics between groups (LA and OA) were evaluated by the Mann-Whitney U-test, Pearson chi-square test, or Fisher exact test, as appropriate.

The data were analyzed by univariable analysis (simple logistic regression) and multivariable analysis (multiple logistic regression). Conversion from LA to OA was the outcome variable. Independent variables were possible risk factors for conversion from laparoscopic to OA included age, sex, ethnicity, histopathology of the appendix, temperature on presentation, duration of symptoms on presentation, and total white blood cell. In this study, all the independent variables were included for multiple logistic regression. All odds ratios (ORs) were presented with 95\% confidence intervals (CI). Statistical analysis was carried out using IBM SPSS Statistics for Windows ver. 22.0 (IBM Corp., Armonk, NY, USA). The limit of significance was set at 0.05 . 


\section{RESULTS}

\section{Patient demographics and clinical characteristics}

One hundred and twenty patients met the inclusion and exclusion criteria and were included in the study. The total numbers of patients with preoperative diagnosis of acute and perforated appendicitis who underwent LA at HUSM during the study period were 83 patients $(69.2 \%)$ and 37 patients $(30.8 \%)$, respectively. In total, 57 females $(47.5 \%)$ were included in the study with the age of $31.6 \pm 16.98$ years old. Exclusion cases were 5 cases, of which 3 cases were excluded for appendicular mass and 2 cases for pelvic inflammatory disease. All 5 cases were treated conservatively with antibiotics and hydrations. Postoperative diagnosis is consistent with the preoperative diagnosis.

Of the 120 patients who underwent initial LA, 33 cases were converted to OA, of which 30 cases were through Lanz incision and 3 cases were through midline laparotomy approach, the decision for midline laparotomy were mainly due to difficult anatomy, which the conversion rate was $27.5 \%$. There were no significant differences between the LA and OA in terms of age, sex, ethnicity, temperature on presentation, duration of symptoms on presentation, and total white blood cells. However, there was a statistical difference in terms of histopathology of the appendix. In 33 patients who were converted to OA, 27 of them (81.8\%) had perforated appendix, while in the LA group, perforated appendix cases consisted of $34.5 \%(\mathrm{P}<0.001)$. Table 1 summarizes patient demographics and clinical characteristics compared between LA and OA subgroups.

\section{Predictors of conversion from laparoscopic to open appendicectomy}

Table 2 shows univariable and multivariable analyses on the predictors of conversion from LA to OA in patients with acute or perforated appendicitis. Using simple logistic regression, histopathology of the appendix (crude OR, 8.55; 95\% CI, 3.18-22.99; P < 0.001 ) was seen to be significant with a P-value less than 0.05 . Simple logistic regression analyses showed that patients presented with perforated appendix have 8.55 times higher odds to convert to OA if compared to others histopathology.

In this dataset, all variables were included in the multiple logistic regression. Multiple logistic regression showed that histopathology of the appendix was the predictor of conversion from LA to OA in patients with acute or perforated appendicitis. After adjustment for age, sex, ethnicity, temperature on presentation, duration of symptoms on presentation, and total white blood cells, the result showed that perforated appendix resulted in greater odds of converting to OA (adjusted OR, 8.82; 95\% CI, 3.13-24.91; $\mathrm{P}<0.001$ ).

\section{DISCUSSION}

In the current era, advancements in laparoscopic surgery and instruments have been exponentially growing. This has led to few
Table 1. Patient demographics and clinical characteristics

\begin{tabular}{|c|c|c|c|c|}
\hline Variable & Total & LA & $O A^{a}$ & P-value \\
\hline No. of patients & 120 & 87 & 33 & \\
\hline Age (yr) & $31.6 \pm 16.98$ & $24.0(18.0)^{b}$ & $27.0(26.0)^{\mathrm{b}}$ & $0.609^{\circ}$ \\
\hline \multicolumn{5}{|l|}{ Sex } \\
\hline Male & $57(47.5)$ & $37(42.5)$ & $20(60.6)$ & $0.077^{e}$ \\
\hline Female & $63(52.5)$ & $50(57.5)$ & $13(39.4)$ & \\
\hline \multicolumn{5}{|l|}{ Ethnicity } \\
\hline Malay & $118(98.3)$ & $85(97.7)$ & $33(100.0)$ & $>0.999^{f}$ \\
\hline Chinese & $2(1.7)$ & $2(2.3)$ & $0(0.0)$ & \\
\hline \multicolumn{5}{|l|}{ Histopathology } \\
\hline Perforated & 57 (47.5) & $30(34.5)$ & $27(81.8)$ & $<0.001^{e}$ \\
\hline Others & $63(52.5)$ & $57(65.5)$ & $6(18.2)^{c}$ & \\
\hline \multicolumn{5}{|c|}{$\begin{array}{l}\text { Temperature on } \\
\text { presentation }\left({ }^{\circ} \mathrm{C}\right)\end{array}$} \\
\hline$\leq 37.5$ & $84(70.0)$ & $61(70.1)$ & $23(69.7)$ & $0.964^{\mathrm{e}}$ \\
\hline$>37.5$ & $36(30.0)$ & $26(29.9)$ & $10(30.3)$ & \\
\hline \multicolumn{5}{|c|}{$\begin{array}{l}\text { Duration of symptoms on } \\
\text { presentation (hr) }\end{array}$} \\
\hline$\leq 48$ & $89(74.2)$ & $66(75.9)$ & $23(69.7)$ & $0.491^{\mathrm{e}}$ \\
\hline$>48$ & $31(25.8)$ & $21(24.1)$ & $10(30.3)$ & \\
\hline \multicolumn{5}{|c|}{ Total white blood cell (x109/L) } \\
\hline$\leq 20,000$ & $104(86.7)$ & 77 (88.5) & 27 (81.8) & $0.372^{f}$ \\
\hline$>20,000$ & $16(13.3)$ & $10(11.5)$ & $6(18.2)$ & \\
\hline
\end{tabular}

Values are presented as number only, mean \pm standard deviation, ${ }^{\mathrm{b}}$ median (interquartile range), or number (\%).

LA, laparoscopic appendicectomy; OA, (conversion from LA to) open appendicectomy.

aThirty cases were converted to Lanz and 3 cases were converted to midline laparotomy. "Histopathological examination of acute appendicitis and suppurative appendicitis. The reason for conversion was difficult anatomy described as extensive adhesions, bowel dilatations with difficulty in identifying the base of the appendix.

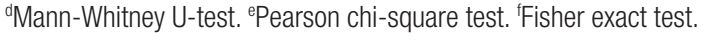

advantages of LA over conventional OA such as reduced postoperative pain, lesser rates of surgical site infections, and shorter hospital stay [12-14]. However, this advantages that LA have over $\mathrm{OA}$ are evened out by the need for longer operating time, more instruments with complex setups, and the need for technical skills, which all translates into higher costs [15]. This study was designed to evaluate the conversion rate and predictors of conversion from LA to OA in patients with acute or perforated appendicitis.

Of the 120 patients who underwent initial LA, 33 cases were converted to OA, which the conversion rate was $27.5 \%$. The conversion rate in our population was higher if compared to Australia and Japan, which were $5.09 \%$ and $10 \%$, respectively $[5,16]$. We believe that this can be due to several factors including patient selection for the laparoscopic approach; the lack of usage in diag- 
Table 2. Predictors of conversion from laparoscopic appendicectomy to open appendicectomy from simple and multiple logistic regression

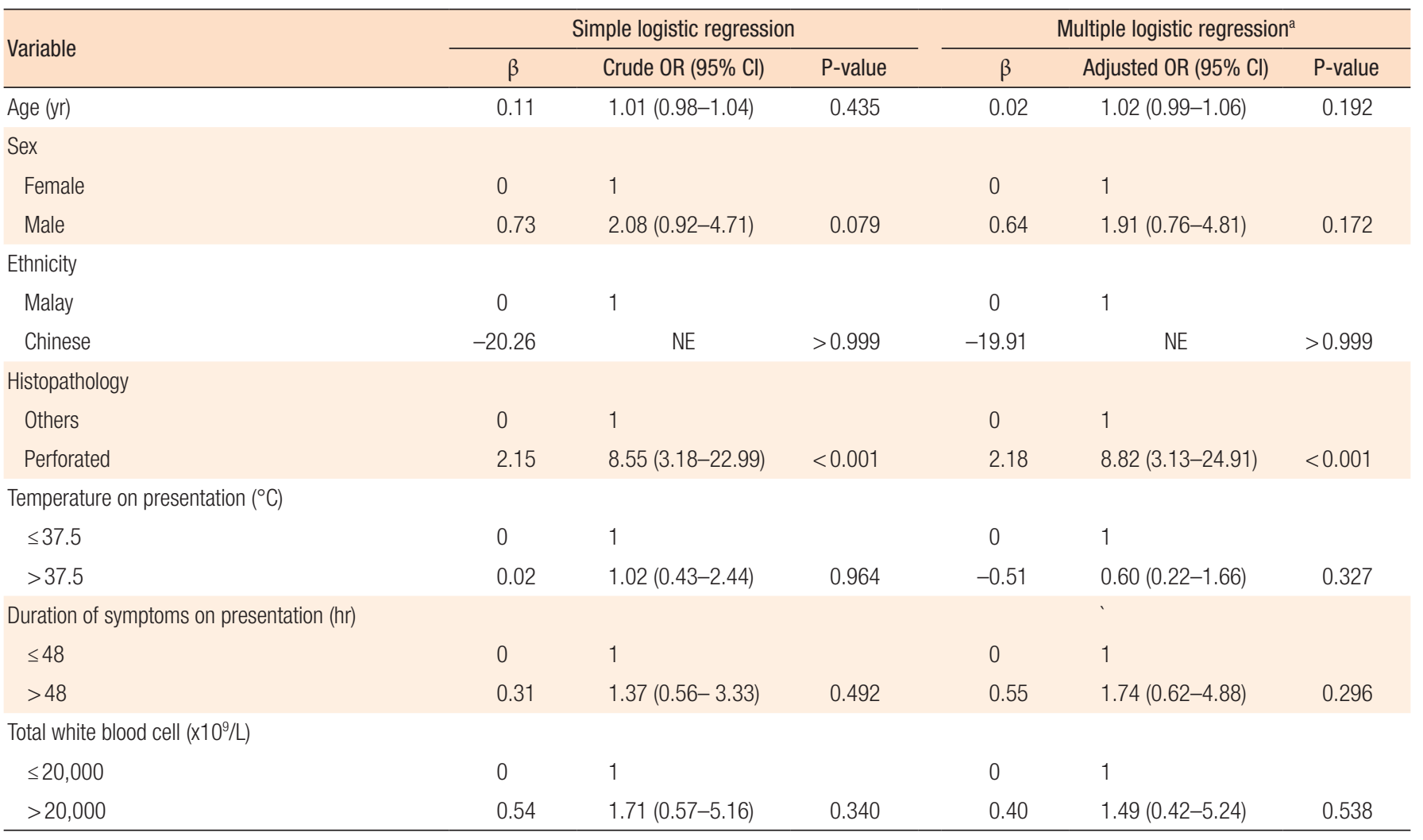

$\beta$, regression coefficient; $\mathrm{OR}$, odds ratio; $\mathrm{Cl}$, confidence interval; $\mathrm{NE}$, not estimable.

Hosmer-Lemshow test $(P=0.727)$, classification table (overall correctly classified percentage $=73.3 \%)$ and Nagelkerke $R^{2}(0.307)$ were applied to check the model fitness.

${ }^{a} \mathrm{All}$ variables were included in the multiple logistic regression.

nostic scans such as computed tomography (CT) or ultrasound and improvement in surgical residents' learning curve. The preoperative radiologic examination (ultrasound scan and CT scan) is not routinely done in our center and only in selected cases. Currently, we do not routinely practice a preoperative CT scan in suspected appendicitis cases. In this study, all the cases were diagnosed clinically and subjected to surgery based on that basis alone. Cases with clinical findings of mass over the right iliac fossa were excluded and managed after an imaging study was done; our approach for appendicular mass has been antibiotic therapy and surgery was done only for failed medical therapy or recurrent appendicitis in this groups.

In our setting, most of our laparoscopic appendicectomies are performed by trainees with the minimum experience of 2 to 3 years of postgraduate experience who are honing their skills and are in the training process which could contribute to this higher conversion rate with their limited technical abilities in comparison with senior surgeons. Furthermore, the learning curve of surgeon from our protocol is to perform LA is after 10 cases as first assistant and 10 cases as the second assistant. Other than that, a better selection of patients may reduce the conversion rate as we can directly proceed to open surgeries in patients with specific criteria.

Our study identified histopathology of the appendix as an independent risk factor for conversion from LA to OA in patients with acute or perforated appendicitis on multivariable analysis. Patients presented with perforated appendix had nearly 9 times higher odds to convert to OA if compared to other histopathology. Other factors such as age, sex, ethnicity, temperature on presentation, duration of symptoms on presentation, and total white blood cells were found to have no association with conversion to OA using multiple logistic regression $(\mathrm{P}>0.05)$.

As the results show, this can be a challenge as the histopathological diagnosis is available only after the surgery has been performed, hence being a limiting factor to rely upon as the early identification of this is crucial to reduce the conversion rate and better planning of surgery for the patient. However, this brings into consideration that, imaging such as ultrasonography (USG) abdomen or high-resolution CT preoperatively can be beneficial to confirm the diagnosis of complicated appendicitis such as gangrenous, phlegmonous, or perforated appendicitis. This can be accurately diagnosed particularly with the usage of CT scans. 
USG is preferred mainly in children and pregnant women due to the reduced risk of ionizing radiation and intravenous contrast usage. A meta-analysis by Keyzer et al. [17] showed that ability of USG to diagnose appendicitis has a sensitivity of 85\% (95\% CI, $79 \%-90 \%)$ and a specificity of $90 \%$ (95\% CI, 93\%-95\%). The advantages of ultrasound include the lack of ionizing radiation and intravenous contrast. Unlike CT or magnetic resonance imaging (MRI), ultrasound can be performed at the bedside. The disadvantage is that ultrasound demonstrates lower diagnostic accuracy than CT or MRI [18]. The ability of CT to diagnose appendicitis in adults reported a sensitivity of 95\% (95\% CI, 95\%-97\%) and a specificity of 96\% (95\% CI, 93\%-97\%) [18]. CT demonstrates higher diagnostic accuracy than ultrasound or MRI. The advantages of CT include less variability in diagnostic performance than ultrasound or MRI. CT scanners and radiologist expertise are more readily available, and the examination is better tolerated by most patients [19]. The disadvantages of CT are patient exposure to ionizing radiation and iodinated contrast [20]. The ability to recognize patients at the highest risk of conversion can help surgeons in selecting patients who may benefit from primary OA, thereby potentially reducing operative time, morbidity, and costs. Although the decision to convert from LA to OA in the operating theatre can be subjective and dependent on individual surgeon skill, and furthermore the cases were primarily conducted by senior registrars in training who have a minimum experience of 2 to 3 years of postgraduate training, identifying objective preoperative predictors associated with conversion to $\mathrm{OA}$ can provide a lower threshold for proceeding with the potentially inevitable open approach, mitigating costs and morbidity. Several studies have demonstrated the role of C-reactive protein (CRP) for the diagnosis of acute appendicitis was $40 \%$ to $87 \%$; the specificity was $53 \%$ to $82 \%$. Significantly elevated CRP level with average readings of $9.76 \mathrm{mg} / \mathrm{dL}$ was shown in complicated appendicitis according to a study by Moon et al. [21]. Based on the results of our study, patients who have been confirmed to have perforated appendicitis may undergo direct open surgery which can significantly reduce the conversion rate and reduce operating time.

We recognize the limitations of this study. This study is focused on acute or perforated appendicitis patients in a single tertiary center and it could be expanded to other centers for future studies. We are also limited by the retrospective nature of this study. Future research is needed to identify other predictors of conversion to OA such as the location of the appendix or any previous abdominal surgeries as well as biomarkers usage such as CRP. As we do not perform CRP biomarker tests and preoperative radiologic examination for our appendicitis cases, we recommended that these methods should be considered for future studies. The usage of CRP readings and preoperative imaging such as USG or CT abdomen, which is objective, relatively inexpensive, simple, and effective can identify this high-risk group of patients and potentially reduce the conversion rate. In this study, we did not cap- ture the parameters for surgical outcomes, for example operation time, postoperative hospital stay, and postoperative complication as we analyzed the conversion rate and its risk factors. Therefore, we are unable to compare these parameters between both groups. In conclusion, the results showed that the conversion rate was high and perforated appendicitis was the predictor for conversion to open in LA. The conversion rate can be improved by proper identification of the high-risk patients.

\section{CONFLICT OF INTEREST}

No potential conflict of interest relevant to this article was reported.

\section{FUNDING}

None.

\section{ORCID}

Nelson Rao Pushpanathan,

https://orcid.org/0000-0002-9968-1699

Mohd Nizam Md Hashim, https://orcid.org/0000-0002-4066-6558

Syed Hassan Syed Abd. Aziz, https://orcid.org/0000-0001-5339-0549

Wan Zainira Wan Zain, https://orcid.org/0000-0001-8019-6063

Rosnelifaizur Ramely, https://orcid.org/0000-0002-2816-810X

Michael Pak-Kai Wong, https://orcid.org/0000-0001-9137-3096

Ikhwan Sani Mohamad, https://orcid.org/0000-0002-9825-0459

Wan Mokhzani Wan Mokhter, https://orcid.org/0000-0002-5622-0307

Maya Mazuwin Yahya, https://orcid.org/0000-0002-3994-6608

Siti Rahmah Hashim Isa Merican,

https://orcid.org/0000-0002-8158-3601

Zaidi Zakaria, https://orcid.org/0000-0003-1644-3546

Andee Dzulkarnaen Zakaria,

https://orcid.org/0000-0002-4826-9725

\section{REFERENCES}

1. Semm K. Endoscopic appendectomy. Endoscopy 1983;15:59-64.

2. Masoomi H, Nguyen NT, Dolich MO, Mills S, Carmichael JC, Stamos MJ. Laparoscopic appendectomy trends and outcomes in the United States: data from the Nationwide Inpatient Sample (NIS), 2004-2011. Am Surg 2014;80:1074-7.

3. Ozmen MM, Zülfikaroğlu B, Tanik A, Kale IT. Laparoscopic versus open appendectomy: prospective randomized trial. Surg Laparosc Endosc Percutan Tech 1999;9:187-9.

4. Tate JJ, Chung SC, Dawson J, Leong HT, Chan A, Lau WY, et al. Conventional versus laparoscopic surgery for acute appendicitis. Br J Surg 1993;80:761-4. 
5. Bui HT, Pho J, Kwok M, Cheng M, Beath A, Chan ST. Risk factors and consequences of conversion in laparoscopic appendectomy. Adv Laparoscopy 2017;1:5-10.

6. Gupta N, Machado-Aranda D, Bennett K, Mittal VK. Identification of preoperative risk factors associated with the conversion of laparoscopic to open appendectomies. Int Surg 2013;98:334-9.

7. Sakpal SV, Bindra SS, Chamberlain RS. Laparoscopic appendectomy conversion rates two decades later: an analysis of surgeon and patient-specific factors resulting in open conversion. J Surg Res 2012;176:42-9.

8. Garg CP, Vaidya BB, Chengalath MM. Efficacy of laparoscopy in complicated appendicitis. Int J Surg 2009;7:250-2.

9. Eypasch E, Sauerland S, Lefering R, Neugebauer EA. Laparoscopic versus open appendectomy: between evidence and common sense. Dig Surg 2002;19:518-22.

10. Finnerty BM, Wu X, Giambrone GP, Gaber-Baylis LK, Zabih R, Bhat A, et al. Conversion-to-open in laparoscopic appendectomy: a cohort analysis of risk factors and outcomes. Int J Surg 2017;40: 169-75.

11. Manuneethimaran T, Mohanapriya T, Arun Kumar K, Nitesh N, Balaji Singh K. The risk factors for conversion of laparoscopic appendicectomy to open appendicectomy. IOSR J Dent Med Sci 2015; 14:33-6.

12. Nana AM, Ouandji CN, Simoens C, Smets D, Mendes da Costa P. Laparoscopic appendectomies: results of a monocentric prospective and non-randomized study. Hepatogastroenterology 2007;54: 1146-52.

13. Wei B, Qi CL, Chen TF, Zheng ZH, Huang JL, Hu BG, et al. Laparoscopic versus open appendectomy for acute appendicitis: a metaanalysis. Surg Endosc 2011;25:1199-208.

14. Li X, Zhang J, Sang L, Zhang W, Chu Z, Li X, et al. Laparoscopic versus conventional appendectomy: a meta-analysis of randomized controlled trials. BMC Gastroenterol 2010;10:129.

15. Kirshtein B, Bayme M, Domchik S, Mizrahi S, Lantsberg L. Complicated appendicitis: laparoscopic or conventional surgery? World J Surg 2007;31:744-9.

16. Abe T, Nagaie T, Miyazaki M, Ochi M, Fukuya T, Kajiyama K. Risk factors of converting to laparotomy in laparoscopic appendectomy for acute appendicitis. Clin Exp Gastroenterol 2013;6: 109-14.

17. Keyzer C, Zalcman M, De Maertelaer V, Coppens E, Bali MA, Gevenois PA, et al. Comparison of US and unenhanced multi-detector row CT in patients suspected of having acute appendicitis. Radiology 2005;236:527-34.

18. Dahabreh IJ, Adam GP, Halladay CW, Steele DW, Daiello LA, Wieland LS, et al. Diagnosis of right lower quadrant pain and suspected acute appendicitis [Internet]. Rockville (MD): Agency for Healthcare Research and Quality (US); 2015 (Comparative Effectiveness Reviews, No. 157) [cited 2020 Oct 19]. Available from: https://www.ncbi.nlm.nih.gov/books/NBK355441/

19. Johnson PT, Horton KM, Kawamoto S, Eng J, Bean MJ, Shan SJ, et al. MDCT for suspected appendicitis: effect of reconstruction section thickness on diagnostic accuracy, rate of appendiceal visualization, and reader confidence using axial images. AJR Am J Roentgenol 2009;192:893-901.

20. Benjaminov O, Atri M, Hamilton P, Rappaport D. Frequency of visualization and thickness of normal appendix at nonenhanced helical CT. Radiology 2002;225:400-6.

21. Moon HM, Park BS, Moon DJ. Diagnostic value of C-reactive protein in complicated appendicitis. J Korean Soc Coloproctol 2011; 27:122-6. 